\title{
NOTA
}

\section{ELIMINAÇÃO DE ANOMALIAS FISIOLÓGICAS, IN VITRO, DE PLÂNTULAS DE PESSEGUEIRO (')}

\author{
WILSON BARBOSA $(2,3)$, FERNANDO ANTONIO CAMPO-DALL'ORTO $(2,3)$ \\ e MÁRIO OJIMA (2)
}

\section{RESUMO}

O experimento objetivou eliminar os sintomas de roseta e ananismo em híbridos de pessegueiro (Prunus persica L. Batsch) precoces, provenientes de cultura embrionária. Essas anomalias fisiológicas aparecem em vista dos inibidores de crescimento presentes nos meristemas apicais dos embriôes. Dois processos de recuperação de vitroplântulas anômalas foram adotados: (a) eliminação da porção apical logo acima da primeira gema, a partir dos cotilédones; (b) manutenção das vitroplântulas por trinta dias em ambiente de vernalizaçāo com temperatura de $5-100 \mathrm{C}$. Os melhores resultados foram obtidos quando se eliminou a dominância do meristema apical; as vitroplântulas mantidas em sala de crescimento emitiram, em cinco dias, brotaçōes novas e normais e se desenvolveram rapidamente. Aquelas submetidas à quebra de endodormência, porém, retomaram parcialmente o desenvolvimento, de forma lenta e anormal.

Termos de indexação: pêssego, cultura de embriāo, roseta, ananismo fisiológico, endodormência, vitroplântulas.

(1) Pesquisa realizada com subsídios do CNPq e FAPESP. Recebido em 3 de janeiro e aceito em 6 de abril de 1989.

(2) Seçâo de Fruticultura de Clima Temperado, Instituto Agronómico (IAC), Caixa Postal 28, 13001 Campinas, SP.

(3) Com bolsa de pesquisa do CNPq. 
A técnica de cultura in vitro de embrióes imaturos possibilita um crescimento eficiente de híbridos de pessegueiro com alta precocidade de maturação dos frutos. Material ċom essa característica genética não acumula reservas cotiledonares suficientes para suprir as necessidades dos embriōes. Suas sementes malformadas, quando retiradas dos frutos e mantidas ao ambiente, desidratam-se rapidamente e perdem o poder germinativo (BARBOSA et al., 1984). No entanto, se mantidas in vitro e mesmo in situ, sob estratificação a frio-úmido $(5-10 \circ \mathrm{C})$, logo que extraídas dos frutos maduros germinam satisfatoriamente (BARBOSA et al., 1985).

O método de germinação in vitro vem sendo utilizado há décadas em programas de melhoramento genético que visam à seleção de pessegueiros precoces (TUKEY, 1933; DAVIDSON, 1933; LAMMERTS, 1942; GILMORE, 1950; KESTER \& HESSE, 1955; MONET, 1968; SMITH et al., 1969; TOLEDO et al., 1980; TOMBOLATO, 1984; BARBOSA et al., 1983, 1985). Apesar do sucesso relatado nos trabalhos de cultura embrionária, são freqüentes as perdas de plântulas devidas às anomalias fisiológicas ocorridas in vitro, das quais são mais comuns: vitrificação, seca apical, ananismo e roseta. As duas últimas afetam a morfologia das folhas, tomando-as assimétricas, retorcidas e débeis, pela redução unilateral de seu crescimento. Essas folhas, examinadas histologicamente, mostraram ser constituidas de células pequenas, compactas, isodiamétricas e sem clorofila (FLEMION \& BEARDOW, 1964).

O presente trabalho objetivou a eliminação dos sintomas prejudiciais às vitroplântulas de pessegueiros, em especial a roseta e o ananismo fisiológico. Procurou-se, assim, proporcionar aumentos substanciais de descendentes com genótipos para alta precocidade de maturação, no programa de melhoramento genético da Seção de Fruticultura de Clima Temperado, IAC.

\section{Material e Métodos}

Utilizaram-se na cultura embrionária sementes das linhagens: IAC 685( $\left.{ }^{4}\right)$ ('Centenária' x 'Tropical'); IAC 785 ('Centenária' x 'Fla. 7-3P'); IAC 1985 ('Dourado-1' x 'Fla. 7-3P') e IAC 1385 (IAC N 2084-14 x 'Tropical'), provenientes de pêssegos de lotes de seleção da Estação Experimental de Jundiai (5).

(4) Os primeiros números referem-se à identificação $\mathrm{e}$, os dois últimos, ao ano do cruzamento.

(5) BARBOSA, W. Melhoramento genético e cultural de frutfieras de clima temperado: pessegueiro, nectarineira e ameixeira. I. Obtençăo de cultivares em diversas épocas de maturaçáo. II. Desenvolvimentó das técnicas de cultura in vitro. Campinas, Instituto Agronómico. Relatório bianual ao $\mathrm{CNPq}, 1988$. $85 \mathrm{p}$. (Nāo publicado) 
O método do preparo dos embriōes à cultura baseou-se em BARBOSA et al. $(1983,1985)$ e SMITH et al. (1969).

O meio de cultura foi composto da solução salina de MURASHIGE \& SKOOG (1962), com as seguintes adiçōes por litro: sacarose $30 \mathrm{~g}$; ágar $6 \mathrm{~g}$; tiamina $1 \mathrm{mg}$; ácido nicotínico 0,5mg; inositol $100 \mathrm{mg}$; glicina $250 \mathrm{mg}$; glutamina $500 \mathrm{mg}$ e asparagina $250 \mathrm{mg}$. O pH foi elevado a $6,0 \mathrm{com} \mathrm{KOH} \mathrm{a} 0,1 \mathrm{~N}$.

Os embriōes, após inoculação nos meios de cultura, foram mantidos em sala de crescimento, com fotoperíodo de 14 horas e temperatura de $28 \pm 2{ }^{\circ} \mathrm{C}$. Em quinze dias de cultura, avaliaram-se a germinaçāo, o desenvolvimento e a presença de roseta e ananismo fisiológico. As vitroplântulas anormais foram separadas em dois grupos de trinta cada uma: o primeiro foi mantido no escuro, por trinta dias, em ambiente frio-úmido de $5-10^{\circ} \mathrm{C}$ e, posteriormente, exposto à luz; o segundo foi submetido a uma desponta apical, eliminando-se o tufo de folhas, logo acima da primeira gema a partir dos cotilédones e mantido sob luz em sala de crescimento.

Transcorridos quarenta e cinco dias, avaliaram-se os tratamentos aplicados.

\section{Resultados e Discussão}

$O$ indice de crescimento dos embrióes cultivados in vitro apresentou-se satisfatório em todas as linhagens utilizadas, cerca de 80 a $90 \%$. Após três dias da inoculação dos embriōes, suas folhas cotiledonares tornaram-se fotossintetizantes; em quinze dias, as vitroplântulas atingiram, em média, $5 \mathrm{~cm}$ de altura, com dois a quatro pares de folhas.

As anomalias fisiológicas foram constatadas na quase totalidade dos descendentes $F_{1}$. $O$ indice de vitroplântulas com roseta aproximou-se de $70 \%$, com ananismo fisiológico $25 \%$ e normais $5 \%$.

Ao apresentar ananismo, as suas folhas pequenas tornaram-se afiladas e com baixo ritmo de crescimento. Nas vitroplântulas com roseta, as folhas tornaram-se enroladas abaxialmente e contorcidas e com bordas e nervuras cloróticas, à similaridade dos sintomas descritos por FLEMION \& BEARDOW (1964) e MONET (1983). O sintoma de seca apical iniciou-se cerca de quinze dias após a germinaçāo, causando a morte das vitroplântulas afetadas.

O epicótilo das vitroplântulas apresentou-se verde-claro e os cotilédones, verde-escuros nas bordas e aciorofilados no centro. As raizes se desenvolveram abundantemente, atingindo, em duas semanas, cerca de $10 \mathrm{~cm}$ de comprimento, demonstrando que não foram afetadas pelas anomalias da parte aérea (Figura 1). 


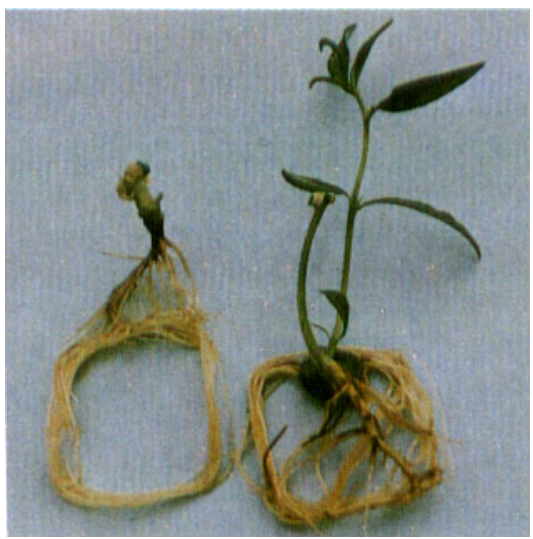

Figura l. Eliminação de anomalias fisiológicas de plântulas de pessegueiro in vitro. $\dot{A}$ esquerda, sintoma severo de roseta; à direita, plântula despontada e recuperada pela brotação lateral normal.

Nas vitroplântulas em que se efetuou o desbaste apical, as brotaçōes surgiram com maior intensidade e vigor a partir de meristemas da base dos cotilédones (Figura 1). A emissão de brotos da gema lateral foi menor e pouco vigorosa. Essas novas brotações não apresentaram anomalias e se desenvolveram normalmente, até serem transplantadas ao solo.

As vitroplântulas mantidas em ambiente frio para vernalização e quebra de endodormência retomaram parcialmente o desenvolvimento, de forma muito lenta e anormal; sua sobrevivência no solo tornou-se comprometida.

Ressaltou-se, de modo incomum na cultura, a rápida germinação das sementes, sem a necessidade do período de estratificaçāo a frio-úmido. Convém observar que a maioria dos pessegueiros exige, para germinaçâo, longos períodos de frio (30-60 dias), para a quebra da endodormência e emissão da radícula (OJIMA \& RIGITANO, 1968; BARBOSA et al., 1986, 1987). Esse tratamento a frio-úmido é necessário para reduzir os niveis de inibidores de crescimento que se encontram endogenamente em altas concentrações nas sementes, impedindo-as de germinar (DIAZ \& MARTIN, 1972; BONAMY \& DENNIS JR., 1977). Durante o periodo de estratificação das sementes, também ocorrem aumentos consideráveis nas concentraçōes de giberelinas $\left(\mathrm{GA}_{3}\right.$ e $\left.\mathrm{GA}_{7}\right)$ (MATHUR et al., 1971). Esse balanço hormonal, entre os promotores e inibidores de crescimento, regula a germinação das sementes dos Prunus em geral. 
Verificou-se, no entanto, que o crescimento vegetativo das vitroplântulas foi limitado, principalmente, por uma dominância (hormonal) do meristema apical; após eliminada (pelo desbaste), permitiu um normal desenvolvimento dos jovens pessegueiros. Pesquisas futuras, sobre a presença e ação de inibidores e promotores de crescimento em plântulas de. pessegueiros subtropicais deverão elucidar o problema.

Os dados deste trabalho evidenciam que as sementes de certas linhagens melhoradas em regiōes de clima subtropical-tropical (a exemplo do Planalto Paulista), podem germinar e as plântulas se desenvolver sem a obrigatoriedade de exposiçāo ao frio-úmido. Com isso, supōe-se que esse material deva conter menores concentrações de inibidores de crescimento, tanto em suas sementes quanto em gemas endodormentes de plantas adultas, conforme BARBOSA et al. (1989). Nessa linha de pesquisa, RASEIRA et al. (1982) verificaram, em pessegueiro, uma correlaçāo altamente significativa entre o número de horas de frio necessárias à germinação das sementes e a quebra da endodormência das plantas, dentro das mesmas linhagens. Assim, de acordo com o sintoma apresentado, é possivel fazer uma pré-seleção dos híbridos menos exigentes de frio, antes mesmo de serem levados ao campo: aqueles que apresentarem severas anomalias fisiológicas poderāo ser eliminados.

O presente método traz vantagens aos trabalhos de cultura de embrião, em especial aos programas de melhoramento genético que visam a cultivares de pessegueiros de maturação bem precoce e altamente adaptados ao clima subtropical-tropical.

\section{SUMMARY}

\section{RECOVERING OF ANOMALOUS PEACH SEEDLINGS GROWING IN EMBRYO CULTURE}

Two methods were studied on peach embryo culture in order to recover seedlings presenting rosette and dwarf development. In the first method almost all the epicotyle was eliminated. Only a small portion of the axe just about cotyledons was left. In the second method, the seedlings were maintained under vernalization for thirty days at $5-10^{\circ} \mathrm{C}$ in a dark room. The results showed that the seedlings submitted to the first method recovered rapidly with normal emission of now shoots. The same was not observed for the seedlings from the second method which developed slowly and still anomalously.

Index terms: peach, embryo culture, rosette, dwarfed seedling, endodormency, vitroplantules. 


\section{AGRADECIMENTOS}

Os autores agradecem a colaboração ao trabalho do Técnico de Laboratório Onivaldo Camargo, do Auxiliar de Campo José de Camargo Barros e da Escriturária Dagmar Vieira Gonçalves Leme.

\section{REFERÊNCIAS BIBLIOGRÁFICAS}

BARBOSA, W.; CAMPO-DALL'ORTO, F.A. \& OJIMA, M. Aspectos reprodutivos das fruteiras de clima temperado, objetivando o melhoramento genético. O Agronómico, Campinas, 35:15-20, 1983. pessegueiros precoces. Bragantia, Campinas, 44(1):465-472, 1985.
- $;-$ \& Relação entre precocidade de maáturação e desidrata- ção das sementê de pêssego. Pesquisa Agropecuária Brasileira, Brasilia, 19(3):337-339, 1984 .

las do pêssego porta-enxerto 'Okinawa': influência de periodos de estratificação e de ácido giberélico. Bragantia, Campinas, 46(2):435-441, 1987.

- - - ; - SAMPAIO, V.R. \& BANDEL, G. Ecofisiologia do desenvolvimento vegetativo e reprodutivo do pessegueiro em regiōes subtropicais: Campinas, Instituto Agronômico, 1989. (Documentos IAC, 17)

; TOMBOLATO, A.F.C.; CAMPO-DALL'ORTO, F.A.; OJIMA, M; RIGITANO, O. \& MARTINS, F.P. Conservação de sementes de pêssegos para produção de porta-enxertos. Campinas, Instituto Agronômico, 1986. 12p. (Boletim técnico, 104)

BONAMY, P.A. \& DENNIS JUNIOR, F.G. Abscisic acid levels in seeds of peach. II. Effects of stratification temperature. Journal of the American Society for Horticultural Science, 102(1):26-28, 1977.

DAVIDSON, O.W. The germination of "non viable" peach seeds. Proceedings of the American Society for Horticultural Science, 30:129-132, 1933.

DIAZ, D.A. \& MARTIN, G.C. Peach seed dormancy in relation to endogenous inhibitors and applied growth substances. Journal of the American Society for Horticultural Science, 97(5):651-654, 1972.

FLEMION, F. \& BEARDOW, J. Histological studies of physiologically dwarfed peach seedlings. I. Structure of anomalous leaves. Contribution from the Boyce Thompson Institute, 22:117-131, 1964.

GILMORE, A.E. A technique for embryo culture of peach. Hilgardia, 20:147-170, 1950.

KESTER, D.E. \& HESSE, C.O. Embryo culture of peach varieties in relation to season of ripening. Proceedings of the American Society for Horticultural Science, 65:265-273, 1955.

LAMMERTS, W.E. Embryo culture an affective technique for shortening the breeding cycle of deciduous tree and increasing germinations of hybrid seed. American Journal of Botany, 29:166-171, 1942. 
MATHUR, D.D.; COUVILLON, G.A.; VINES, H.M. \& HENDERSHOTT, C.H. Stratification effects on endogenous gibberellic acid (GA) in peach seeds. HortScience, 6:538-539, 1971.

MONET, R. Méthode permettant l'obtention de plants à partir d'embryons de variétés très précoces chez le pêcher. Annuel Amélioration Plantes, 18:85-91, 1968.

\section{. Le pêcher: génétique et physiologie. Paris, INRA et Masson, 1983. 133p.}

MURASHIGE, T. \& SKOOG, F. A revised medium for rapid growth and bioassays tobacco tissue cultures. Physiologia Plantarum, 15:473-479, 1962.

OJIMA, M. \& RIGITANO, O. Estudo de germinação de sementes de pêssego (Prunus persica L. Batsch) de diversas variedades. Bragantia, Campinas, 27:XLI-XLV, 1968. (Nota, 11)

RASEIRA, M.C.B.; PAIVA, E. \& LEAL, M.L. Necessidade de frio em pessegueiro: correlaçāo entre sementes e planta. Pelotas, 1982. 22p. (EMBRAPA-UEPAE de Cascata. Boletim de Pesquisa, 2)

SMITH, C.A.; BALEY, C.H. \& HONGH, L.F. Methods for germinating seeds of some fruit species with special reference to growing seedlings from immature embryons. New Jersey, Agricultural Experiment Station, 1969. 29p. (Bulletin, 823)

'TOLEDO, W.; HUGARD, J. \& JONARD, R. Amélioration de la technique d'obtention de plants de semis de pêcher (Prunus persica L. Batsch) à partir de graines du cultivar de maturité précoce Springtime. Comptes Rendus Hebdomadaires des Séances de L'Académie Science, Paris, 290:539-542, 1980.

TOMBOLATO, A.F.C. Étude de l'influence de facteurs agissant sur le développement de l'embryo du pêcher (Prunus persica L. Batsch) "in situ" et "in vitro" jusqu'a a l'obtention de le jeune plant. Universidade de Bordeaux, II, 1984. 190p. Thèse (Docteur)

TUKEY, M.B. Growth of peach embryo in relation to growth of fruit and season of ripening. Proceedings of the American Society for Horticultural Science, 30:209-218, 1933. 